\title{
PRÁTICAS EDUCATIVAS DOS TRABALHADORES DE ENFERMAGEM DE UM HOSPITAL DO VALE DO RIO PARDO: CLASSE, CULTURA E FORMAÇÃO NAS RELAÇÕES ENTRE OBJETIVIDADE E SUBJETIVIDADE
}

\author{
Aline Mesquita Corrêa ${ }^{1}$ \\ Jessica Fell ${ }^{2}$ \\ Moacir Fernando Viegas ${ }^{3}$
}

\begin{abstract}
RESUMO
$\mathrm{O}$ artigo apresenta resultados parciais da pesquisa Práticas Educativas dos Trabalhadores de Enfermagem de um Hospital do Vale do Rio Pardo: Classe, Cultura e Formação nas Relações entre Objetividade e Subjetividade. O objetivo principal é descrever e analisar a produção de saberes que ocorre nas relações de produção e, especificamente, nas relações informais da prática social dos trabalhadores de enfermagem de uma unidade hospitalar. Sua relevância está associada ao significado de uma melhor compreensão das relações entre os saberes contidos nos protocolos institucionais e os que estão presentes na atividade realizada pelos trabalhadores. Para tanto, buscou-se apoio teórico no materialismo histórico e dialético, na psicologia do trabalho e na ergologia. A metodologia utilizada foi a aplicação de questionários, com entrevistas do tipo semiestruturada, histórias de vida e grupos de discussão. Como resultados parciais do processo de pesquisa, discute-se na presente escrita dados que nos permitem análises acerca dos sentidos da pesquisa para o trabalhador e para trabalhadora da saúde, bem como também para a instituição.
\end{abstract}

Palavras-chave: Educação e Trabalho. Ergologia. Saberes dos Trabalhadores.

\begin{abstract}
The article presents results of the research Educational Practices Workers of Nursing hospital at Rio Pardo Valley: Class, Culture and Training in relations between Objectivity and Subjectivity. The main objective is to describe and analyze the knowledge production that occurs in the relations of production and, specifically, the informal relationships of the social practice of nursing in a hospital. Its relevance is associated with the significance of a better understanding of the relationships between the knowledge contained in institutional protocols and those that are present in the activity carried out by workers. To do so, we sought theoretical support in the historical and dialectical materialism, in work psychology and ergology. The methodology used was questionnaires, semi-structured interviews with kind, life stories and discussion groups. As partial results of the research process, it is argued in the written data analyzes that allow us about the way the search for the worker and worker health and also for the institution.
\end{abstract}

Keywords: Education and work. Ergology. Workers' knowledge.

\footnotetext{
${ }^{1}$ Mestranda em Educação pela Universidade de Santa Cruz do Sul - UNISC. <alinemcorrea@mx2.unisc.br>

${ }^{2}$ Graduanda em Psicologia pela Universidade de Santa Cruz do Sul - UNISC. <jeh-fell@ hotmail.com>

${ }^{3}$ Doutor em Educação e Professor Adjunto do Departamento de Educação e Programa de Pós-Graduação

Mestrado em Educação da Universidade de Santa Cruz do Sul - UNISC. 〈mviegas@ unisc.br>
} 


\section{INTRODUÇÃO}

A pesquisa está inserida na linha de pesquisa Educação, Trabalho e Emancipação do PPGEdu UNISC e integra o estudo internacional "Trabalhar na Nova Gestão Pública. Significados, conflitos e resultados. Do conjunto de estudos acerca do trabalho que já vinhámos realizando em outros momentos, a presente pesquisa sobre a qual se escreve, nessa integração se utiliza de alguns dispositivos metodológicos e teóricos em sua constituição.

$\mathrm{Na}$ ação de trabalhar se imbricam algumas questões que, cotidianamente, vêm sendo estudadas, não com a intenção de definir ou conceituar de forma exata o fenômeno trabalho, mas para questionar-se e pensar acerca do trabalho e as suas diferentes formas de se fazer presente na vida do homem e da mulher. Mais que estudá-lo, buscamos contribuir para o contemporâneo debate acerca do processo de educação que ocorre no trabalho. Para este estudo, nos apoiamos em teorias que ajudam a compreender que o trabalho também constitui um fenômeno educativo, protagonizado pelas ações prescritas e pela atividade realmente realizada.

A partir de nossos pressupostos teóricos, compreendemos que todo processo de trabalho perpassa uma ação educativa na qual o trabalhador e as trabalhadora se constituem. No entanto, cada processo possui uma especificidade. $\mathrm{O}$ artesão trabalha com um produto - a matéria prima -, o lavrador se utiliza de ferramentas para o seu trabalho, em ambos os exemplos, trata-se de uma ação educativa, que se dá com matérias inanimadas, mas, também, imprevisíveis, pois podem quebrar, ser de má qualidade. Enfim, há infinitas possibilidades de ambos os trabalhadores renormalizarem o trabalho e, assim, comporem o que compreendemos por práticas educativas no trabalho.

Em nosso caso, estudamos o profissional e a profissional da enfermagem, cujo trabalho não se constitui com uma matéria bruta ou inanimada, mas, sim, com um corpo que tem sentimentos. É um trabalho com seres humanos, os quais apresentam situações de saúde específicas e exigem do trabalhador e da trabalhadora de enfermagem uma renormalização continua de seu trabalho.

$\mathrm{Na}$ atividade profissional, independente de sua especificidade, existem normas, diretrizes, currículos ou protocolos. Na saúde, os trabalhadores e trabalhadoras contam com os protocolos institucionais, que têm como base subsidiar a ação do trabalho. Porém, no momento de realizar o trabalho, algumas ações não acontecem tal como os protocolos orientam. No estudo da teoria ergológica do trabalho isto é colocado como burlar. Schwartz (2000) disserta que o ser humano ao trabalhar burla as normas e os protocolos de seu trabalho. 
Nesta mesma teoria, sobretudo, há uma explicação para isso. Esta se refere à diferença entre a atividade prescrita e a atividade efetivamente realizada, afirmando que essa ação de burlar o trabalho se faz necessária, ainda mais quando se trata do trabalhador e da trabalhadora de saúde, que realizam sua ação com seres humanos.

Diante disso, o projeto de pesquisa que está em andamento, se volta para o estudo de como ocorre a prática educativa em saúde e o processo de educação no trabalho, levando em consideração os aspectos do uso de si e outras questões que não se separam do ser humano quando este está na sua ação de trabalhar.

Além da ergologia, foi utilizada como base teórica a teoria crítica, o materialismo histórico e dialético e a psicologia social do trabalho. Contamos, também, com o apoio teórico da filosofia, estudos da teoria crítica representados por Adorno e Horkheimer e o marxismo de Marx e Thompson.

$\mathrm{O}$ artigo apresenta alguns questionamentos, como: em que medida essas práticas educativas apresentam algo de novo? Como se relacionam com os elementos culturais da formação do trabalhador? Como são produzidos esses saberes pelos trabalhadores? De que forma eles são apropriados pelo processo de produção? Diante destes questionamentos, as observações realizadas focaram desde cedo em perceber as questões voltadas para as culturas dos trabalhadores, saberes, processos de trabalho.

A pesquisa é caracterizada como qualitativa, de cunho descritivo. Foi realizada a aplicação de questionários com aproximadamente 200 trabalhadores e trabalhadoras da enfermagem. Pretende-se ainda a realização de entrevistas semi-estruturadas aprofundadas com até 20 sujeitos e a constituição de um grupo de discussão com enfermeiros, enfermeiras e técnicos e técnicas de enfermagem, sendo que neste grupo debateremos questões mais aprofundadas. Este mesmo questionário será lançado no banco de dados da Universidade Autônoma de Barcelona.

A atividade de trabalho, por mais mecânica que seja, não pode ser considerada pura execução. Sempre constitui alguma forma expressa pelo sujeito, representando, assim, a renormalização da atividade, o uso de si que caminha, então, para a ação educativa. Na perspectiva ergológica, essa renormalização do trabalho permite ao trabalhador fazer história, uma espécie de realizar-se na sua atividade. 


\title{
2 A DICOTOMIA DO TRABALHO E AS POSSIBILIDADES DE REALIZAÇÃO DO SUJEITO
}

O trabalho, dada sua complexidade e todas as dimensões em que se apresenta concretamente, dificulta a definição de um conceito. Isto ocorre porque a ação de trabalhar se constitui em um contexto de faces e interfaces, de sentidos amplos e também particulares. No contexto social e teórico sob o enfoque crítico, o trabalho pode ser uma forma de realização; para outros, de sobrevivência; ainda há filósofos, como Meszáros (2005), que concebem o trabalho como metabolismo de exploração no sistema capitalista.

Concebemos o trabalho sob a perspectiva da teoria crítica. Sendo assim, procuramos não nos precipitar em definições concretas acerca do trabalho, mas, sim, estudá-lo em suas dimensões e indagar, à luz dos pressupostos críticos, sociológicos e ergológicos, o fenômeno trabalho e suas implicações na sociedade. Schwartz (2000) escreve sobre a particularidade do trabalho, afirmando que:

\begin{abstract}
A variabilidade de todas as situações de trabalho faz com que os problemas não sejam resolvidos mas constituídos. (...) toda situação de trabalho é, de alguma forma, experiência, reencontro: ela coloca à prova normas e valores antecedentes em uma situação histórica sempre em parte singular. (...) A atividade de trabalho propõe, convoca, impõe escolhas e arbitragens. Nunca é o retorno do mesmo. A realidade e a materialidade desses encontros obriga a levar a sério o fato de que os valores são também convocados em uma espécie de prova de fogo que os avalia e julga segundo sua capacidade de tratar esses reencontros (p.38).
\end{abstract}

A partir de leituras em Marx e Engels (2005), pode-se compreender diferentes modos de trabalho: aquele através do qual o homem e a mulher satisfazem suas necessidades com os produtos do trabalho e transformam a si mesmos e a natureza, desenvolvendo ambos; aquele abstrato, quando o homem e a mulher utilizam a força física e mental e geram valor de troca nas mercadorias; e trabalho produtivo, aquele no qual o homem produz mercadorias. No entanto, na teoria marxista, podemos compreender que ocorreu um processo de transformação do trabalho enquanto atividade humana para a sua formatação atual, muitas vezes fonte de alienação humana.

Ainda, na sociedade capitalista, o trabalho se tornou, também, um modo de classificação e corrosão do caráter do homem e da mulher. O trabalho os dita, constrói sentidos até mesmo alienados e alienantes. Marx e Engels (2005) nos permitem a reflexão, quando dissertam que: 
Da maneira como os indivíduos manifestam sua vida, assim são eles. O que eles são coincide, portanto, com sua produção, tanto com o que produzem como com o modo como produzem. O que os indivíduos são, por conseguinte, depende das condições materiais de sua produção (p.45).

Devido a essa relação dos meios de produção com o ser humano, Marx e Engels consideram, contudo, o trabalho como algo fundamental para a existência humana. No pressuposto teórico da ergologia, o trabalhador e a trabalhadora cotidianamente renormalizam o seu trabalho. Esta ação não se dissocia do trabalho, visto que, em determinadas condições, nos momentos em que realiza uma ação de trabalho, faz-se sempre um uso de si.

O uso de si, assim como também o uso de si pelo outro, são abordados pelo filosofo Schwartz (2000) quando este discute estas renormalizações no trabalho. Na pesquisa, nos voltamos mais para este uso de si, compreendendo que:

\footnotetext{
Ora, essa infidelidade deve ser gerida: e gerida justamente não como uma execução (senão dir-se-ia que o meio é fiel), mas como um "uso de si", ou seja, é preciso fazer uso de suas próprias capacidades, de seus próprios recursos e de suas próprias escolhas para gerir essa infidelidade, para fazer alguma coisa. Isso que eu chamo de "vazio de normas", porque aí as normas antecedentes são insuficientes - visto que não há somente execução (p. 37).
}

Compreendemos que o uso de si significa um caminho para as práticas educativas que se constituem no ambiente de trabalho, uma vez que nesta ação, além de renormalizar o seu trabalho, o ser humano também expressa as questões de classe, cultura e formação, perpassando também pelas relações de trabalho. Nas palavras de Schwartz (2000, p. 38) "As normas não antecipam tudo". Então, trabalhar é arriscar, fazer "uso de si”.

Brito (2004), a partir da teoria ergológica, disserta sobre o processo de libertação que se constitui no trabalho a partir das renormalizações, afirmando que:

Numa perspectiva ergológica, muito mais do que simples conformação de um perfil de adoecimento e morte resultante da exploração da força de trabalho, o trabalho em sua complexidade pode e deve ser analisado e reconhecido numa perspectiva libertadora, no seu papel na vida das pessoas e na configuração da defesa da vida. As lógicas de subordinação existem, porém jamais serão sufi cientes para aniquilar as subversões renormalizantes (p. 18).

Também, quando pensamos a partir da teoria crítica, podemos compreender que esta nos possibilita questionamentos acerca da ação de trabalhar: realização no trabalho, ação laboral e outros aspectos, que levam à compreensão de que o homem e a mulher que trabalham não são simplesmente alienados. A partir dos estudos críticos que refletem esta 
compreensão em união à ergologia, firmamos nossos ideais para pensar o trabalho também enquanto um fenômeno educativo. Odonne (1984) afirma que:

Tenho constatado, de maneira um pouco indireta, que existe entre os sujeitos que exercem a mesma atividade de trabalho, uma diversidade profissional. Ela é constituída, aparentemente, de elementos de todas as ordens: políticos, culturais, étnicos, que se imbricam tão estreitamente entre si que é difícil interpretar de outra maneira do que uma síntese eminentemente previsível de particularidades individuais, subjetivas (p.29).

Ainda, a partir da teoria da ergologia, da qual nos utilizamos para pensar a respeito dos saberes que se produzem no trabalho e que não podem ser dissociados da ação que é realizada no trabalho, Cunha (2009) disserta que:

Todo meio de trabalho é constituído por normas antecedentes que ao serem encontradas nas situações laborais pelo homem produtor, geram renormalizações, até mesmo porque sem estas últimas, o trabalho prescrito não pode ser realizado. Para a ergologia, se a distância entre o prescrito e o real no trabalho é inevitável, neste hiato se inscrevem as renormalizações. Mesmo obedecer às normas antecedentes já é praticar escolhas. E ao operar nos interstícios das normas antecedentes, o homem faz história ${ }^{4}$ (p. 02).

A partir da escrita da autora, pode-se compreender que os trabalhadores da enfermagem renormalizam o seu trabalho no cotidiano. Esta é uma necessidade, pois faz parte da atividade humana. Schwartz (1996) afirma que:

Toda forma de atividade em qualquer circunstância requer sempre variáveis para serem geridas, em situações históricas sempre em parte singulares, portanto escolhas a serem feitas, arbitragens - às vezes quase inconscientes - portanto, o que eu chamo de "usos de si", "usos dramáticos de si". Simplesmente, em nossa época, é verdade que a forma do trabalho como emprego ou mercadoria é, de um modo geral, quer dizer, nem sempre, o modo mais rico de ativação dentre estes modos "dramáticos" (p.151).

Em Schwartz (1996), compreende-se que o trabalho enquanto atividade humana é sempre um campo de tensão entre normas antecedentes estabelecidas e renormalizações. As renormalizações que ocorrem no trabalho são frutos que se constituem a partir do momento em que o trabalhador e a trabalhadora, com seu conjunto de saberes e vivências, interpretam o trabalho prescrito e o realizam, colocando um pouco de si. Como apoio a nossa escrita, citamos Trinquet (2010):

\footnotetext{
${ }^{4}$ Compreendemos que não somente o homem, mas também se torna necessário fimar que a mulher também faz história, tendo em vista também que grande parte dos sujeitos que atuam na enfermagem são mulheres.
} 
A atividade é tomada no sentido de atividade interior. É o que se passa na mente e no corpo da pessoa no trabalho, em diálogo com ela mesma, com o seu meio e com os "outros". Embora essa seja uma ideia abstrata, é muito fecunda e eficaz. Definitivamente, é o que faz com que o trabalho possa se realizar e, de fato, se realiza (p.96).

A citação acima nos permite compreender que o uso de si é o que permite que o trabalho seja realizado. Consideramos, também, que dessa forma o trabalhador e a trabalhadora se realizam na sua relação com a objetividade do trabalho e, assim, os saberes se constroem.

\section{RESULTADOS PARCIAIS}

Após estudo aprofundado de nossas bases teóricas, com um olhar voltado para as práticas educativas em saúde, especificamente entre os trabalhadores e trabalhadoras da enfermagem, os enfermeiros, as enfermeiras e a gestão do hospital, percebe-se que o fato da instituição participar de uma pesquisa que compõe um estudo internacional é algo muito importante e positivo. Afirma-se que traz benefícios para a entidade hospitalar e para os sujeitos participantes, permitindo um melhor conhecimento de seu trabalho e de suas habilidades profissionais, assim como das relações entre esses e os saberes contidos nos protocolos institucionais.

Os protocolos institucionais se referem à discussão que vimos no decorrer do artigo no que se refere às distâncias ou proximidades existentes entre o trabalho prescrito, neste caso os protocolos, e o trabalho real, que se refere ao trabalho de fato realizado. A pesquisa tem possibilitado o conhecimento das relações entre os saberes contidos nos protocolos e as atividades realizadas. A relevância da pesquisa se constitui no ideal de que as práticas educativas nos locais de trabalho possuem um novo significado a partir do momento que os trabalhadores explicitam e pensam sobre seus saberes subjetivos frente às suas realidades objetivas.

O trabalho dos enfermeiros e enfermeiras, técnicos e técnicas de enfermagem assim como os demais processos de trabalho, detém uma especificidade. No entanto, é uma atividade que também se constitui em dilemas, os quais levam a questionamentos acerca da valorização destes profissionais e um debate contemporâneo no que tange a educação em saúde. No presente momento temos cerca de 205 questionários aplicados com enfermeiros e 
enfermeiras, técnicos e técnicas de enfermagem já lançados no Banco de Dados, fornecendo, assim, subsídios para fazermos algumas considerações.

De início, os trabalhadores e trabalhadoras de enfermagem e a gestão do hospital, sujeitos da pesquisa, colocaram que o fato do hospital participar de uma pesquisa que compõe um estudo internacional é algo muito importante e positivo para a instituição. Esta afirmação vai se fortalecendo no decorrer da pesquisa, quando confidenciam que esperam mudanças, anseiam pelos resultados e descrevem que pesquisas do cunho que realizamos precisam acontecer mais vezes no hospital.

Retomando a questão dos dilemas existentes no trabalho em enfermagem, estes se fundamentam em Trabalho e Valorização, Trabalho e Reconhecimento, Trabalho $e$ Remuneração. Esses dilemas da profissão são discutidos pelos enfermeiros e enfermeiras, técnicos e técnicas de enfermagem, antes da aplicação dos questionários, quando estes dialogam entre si e também são realizadas colocações nos questionários. O que mais aparece nos questionários é a questão do Trabalho e Remuneração-Reconhecimento.

Ao provocar reflexões, a pesquisa traz benefícios para os sujeitos participantes, sobretudo de cunho reflexivo. Nas escritas contidas no final dos questionários, os trabalhadores e trabalhadoras relatam que a experiência de refletirem sobre o seu trabalho é muito válida, uma vez que, no cotidiano, na correria do dia a dia, essa reflexão acerca do trabalho acaba não acontecendo.

Nas observações que acontecem quando estamos no ambiente de pesquisa, os trabalhadores e trabalhadoras de enfermagem dialogam consideravelmente acerca do trabalho e, nesses diálogos, algumas colocações chamam atenção. Uma destas questões é o tempo de trabalho na sociedade capitalista. Em uma tarde, uma das enfermeiras colocou a suas colegas que trabalhar em mais de um emprego é sinônimo de se cansar mais, uma vez que:

Quando trabalhamos em um emprego, a remuneração é suficiente para vivermos, porém se arrumarmos outro emprego para sobrar dinheiro, acabamos consumindo mais ainda, gastando mais, e então o trabalho que era para garantir um extra, já gera serviço extra e não dinheiro extra.

Nessas discussões já se torna possível percebermos as dimensões do trabalho, e suas faces e interfaces na vida destes sujeitos. Percebe-se também que há indícios de uma prática educativa na qual o trabalhador e a trabalhadora conseguem perceber a lógica do trabalho e do processo de trabalhar na sociedade de consumo. Alguns/mas estavam saindo do trabalho, outros/as chegando e havia ainda quem estivesse no horário de trabalho. Pouco a pouco, cada 
sujeito, na sua condição de tempo, participou da pesquisa. Não houve grande diferença entre os variados tempos, no momento de participação. No entanto, os que estavam em seu turno de trabalho demonstravam certa pressa, uma vez que precisavam trabalhar.

Consideramos que estes resultados, que se voltam para os sujeitos da pesquisa, são resultados de cunho importante, pois já há um retorno para esses trabalhadores e trabalhadoras de enfermagem. Em muitos casos, ao participarem da pesquisa, eles expõem seus desejos de mudança em seus setores de trabalho e colocam, ainda, as angústias que lhes têm acompanhando cotidianamente.

Este primeiro momento da pesquisa nos permite diferentes análises, as quais precisam ser detalhadas e organizadas a longo prazo em conjunto com os demais dados que serão levantados nas próximas etapas, uma vez que ainda estamos no processo de aplicação dos questionários com os trabalhadores e trabalhadoras. No entanto, expressões como as colocadas abaixo por enfermeiras permitem algumas considerações no que se refere às condições de trabalho e ação destas trabalhadoras.

Ufa, desabafei, este questionário nos faz refletir sobre questões importantes acerca da qualidade de vida e expectativa de trabalho. Algo que raramente fazemos. "Me sinto sendo exaustada”.

É uma forma de podermos [nos] expressar, já que muitas vezes somos tratados com relação a esses fatores. Penso que somos (nós técnicos enfermagem) muito mal remunerados por tudo que desenvolvemos em nosso local de trabalho. Prá mim é gratificante o que eu faço, mas ter o reconhecimento e o devido valor de nossas obrigações não temos este privilégio.

Que o funcionário fosse chamado pela chefia para receber elogio. Nos dias de hoje são chamados para ganhar ou receber reclamação ou chamar atenção do que fez. errado, não é elogiado pelo que fez certo.

Estas escritas, cada uma com sua particularidade, expressam um pouco do cotidiano das trabalhadores da enfermagem em termos de qualidade de vida no trabalho. Pode-se perceber que as práticas educativas, o uso de si, também enquanto processo de educação no trabalho, apresentam-se de forma marcante.

No que tange as relações no ambiente de trabalho, neste primeiro momento, estas parecem estar em conflito. A formação destas relações apresenta fragilidades com os colegas de trabalho, com os clientes da instituição hospitalar e com a gestão da instituição. A fragilidade das relações muito se volta para as questões de valorização e reconhecimento dos trabalhadores e trabalhadoras da enfermagem. 
Este reconhecimento por sua vez, não refere-se apenas a remuneração, mas ao reconhecimento que compreendemos a partir de Honneth (2003) ser filosófico, ou seja nos aspectos sociais, afetivos, emocionais, solidariedade, direito e entre outros.

O estudo das práticas educativas, que se constituem no ambiente de trabalho, colabora com o atual debate que desconstitui alguns princípios de que o homem e a mulher são é simplesmente executores de tarefas. Sabe-se e fundamenta-se teoricamente que o ser humano pensa para agir diante das prescrições e protocolos institucionais que fomentam o seu trabalho.

A experiência proporcionada pelos estudos teóricos e a vivência prática que tem se dado através da pesquisa empírica, o modo como os enfermeiros e enfermeiras, técnicos e técnicas de enfermagem, chegam à sala de aplicação dos questionários, suas fisionomias, assuntos e as capacitações que ocorrem na instituição hospitalar nos fornecem ferramentas para considerações acerca da organização do trabalho. Não se trata de uma análise de ótica comportamental, nem tampouco intuitiva, mas, sim, uma leitura do que o ambiente e a ação de cada sujeito expressa.

A divisão do trabalho ocorre de forma muito marcante na instituição. Uma vez que trabalha com seres humanos, e o fragmenta por partes, cada setor da área hospitalar cuida de uma parte específica deste ser. Os trabalhadores e trabalhadoras de enfermagem que atuam no maternal se tornam estranhos aos trabalhadores e trabalhadoras, também de enfermagem, que atuam na UTI ${ }^{5}$. Isto pôde ser percebido no momento de aplicação dos questionários, pois os sujeitos se organizam em grupos de conhecidos.

Estes grupos geralmente se constituem de sujeitos que atuam no mesmo setor e tem reflexo na maneira como se acomodam nos espaços da sala de aplicação de questionários. Aqueles/as que trabalham no Pronto Atendimento possuem pouco convívio com aqueles/as que trabalham na área de Pediatria e, assim como o trabalho dividido, as relações no ambiente de trabalho, numa perspectiva macro, também se tornam fragmentadas. É como se fosse uma grande esteira, onde se pensa em partículas do todo e, então, a integralidade do cuidado também sofre alterações.

No decorrer das demais etapas da pesquisa, acredita-se que os dados nos permitirão mais análises, a fim de encontrarmos pontos norteadores para as questões postas inicialmente. Percebe-se, também, que categorias emergentes, ações que sempre nos surpreendem enquanto pesquisadores e pesquisadoras, se farão presentes na trajetória de pesquisa.

\footnotetext{
${ }^{5}$ Local no qual as pessoas recebem um tratamento intensivo, quase sempre o último tratamento possível para seu caso de doença.
} 


\section{CONSIDERAÇÕES FINAIS}

Pesquisar o trabalho é uma ação delicada, pois também é um processo de trabalho que, em sua especificidade, se constitui particularidades.

$\mathrm{Na}$ sociedade mediada pelas relações mercantis, o trabalho enquanto processo de criação e realização do homem e da mulher, processo de construção histórica, acabou cedendo lugar para o trabalho visto como uma forma de suprir as necessidades de nossa existência. Trabalhamos porque precisamos comer, nos vestir, ter acesso à saúde, locomoção, enfim. Contudo, a teoria da ergologia e pressupostos críticos evidenciam que este trabalho na sociedade capitalista também permite ao ser humano essa realização e o fazer história.

É através então do uso de si, da renormalização, das transgressões e tensões do trabalho, que o trabalhador e a trabalhadora encontram na sua atividade, essa realização e conseguem, de algum modo, fazer o uso de si. Assim, também percebemos o fenômeno educativo que acontece nos processos de trabalho.

Na primeira etapa da pesquisa, que se refere à aplicação de questionários voltados para a qualidade de vida dos trabalhadores e trabalhadoras de enfermagem, já conseguimos perceber o quanto esse processo educativo se constitui cotidianamente no trabalho dos/as profissionais da enfermagem. Refletindo ainda a partir do que disserta Odonne (1986), podemos constatar o modo como os processos de formação, classe e cultura não se dissociam do ser humano quando este está a realizar o seu trabalho.

As práticas educativas, portanto, são inerentes ao trabalho na enfermagem, uma vez que, ao tencionar o seu trabalho e fazer o uso de si, o trabalhador e a trabalhadora já se integram em um processo de trabalho que produz uma experiência e um aprendizado.

\section{REFERÊNCIAS}

BRITO J. Saúde do trabalhador: reflexões a partir da abordagem ergológica. In: FIGUEIREDO, M; ATHAYDE, M.; BRITO, J.; ALVAREZ, D. (Org.) Labirintos do trabalho: interrogações e olhares sobre o trabalho vivo. Rio de Janeiro: DP\&A, 2004.

CUNHA, D. M. Notas Conceituais sobre Atividade e Corpo-si na Abordagem Ergológica do Trabalho. GT Trabalho e Educação - $\mathrm{n}^{\circ}$ 09, 2008. Disponível em: http://30reuniao.anped.org.br/. Acesso em: 25 de Jan. 2014

MARX, K.; ENGELS, F. A ideologia alemã. São Paulo: Boitempo, 2005. 
HONNETH, A. Luta por reconhecimento: a gramática moral dos conflitos sociais. São Paulo: Ed. 34, 2003.

MÉSZÁROS, I. Para além do capital: rumo a uma teoria da transição. São Paulo: Boitempo, 2005.

ODDONE, I. . Ambiente de trabalho: a luta dos trabalhadores pela saúde. São Paulo: Hucitec, 1986.

TRINQUET, P. Trabalho e educação: o método ergológico. Revista HISTEDBR On-line, Campinas, número especial, p. 94-110, 2010. Disponível em: 〈http://www.histedbr.fae. unicamp.br/revista/edições/38e/art07_38e.pdf>. Acesso em: 12 fev. 2014.

SCHWARTZ, Y. Circulações, dramáticas, eficácias da Atividade Industriosa. Revista FIOCRUZ On-line, Rio de Janeiro, v. 2, n. 1, p.33-55, 2004. Disponível em: <http://www.revista.epsjv.fiocruz.br/upload/revistas/r61.pdf>. Acesso em: 12/05/2012 Trabalhos e uso de si. Revista Proposições, v. 11, p. 34-50, 2000. Trabalho e valor. Revista Idéias, v. 3, n. 2, p.147-158, 1996. 